\title{
Neonatal infection in premature infants and use of human immunoglobulin
}

\author{
S P CONWAY, D R N GILLIES, AND A DOCHERTY
}

University Department of Paediatrics and Child Health, and Regional Neonatal Unit, General Infirmary, Leeds

SUMMARY In an open study 120 consecutively admitted premature babies of 32 weeks' gestation or less, were randomised to receive weekly intramuscular injections of human normal immunoglobulin $(50 \mathrm{mg} / \mathrm{kg})$. There was no significant difference between the number of babies in the treated and untreated groups who had at least one episode of infection, but the total number of infective episodes was substantially less in the treated group $(n=22)$ compared with 40 in the non-treated group. Three babies died from overwhelming infection and three babies developed necrotising enterocolitis, all in the group that had not been treated. Serum IgG concentrations were significantly higher in the treated group by the age of 2 weeks but remained consistently below those of full term babies of similar postnatal age. Administration of human immunoglobulin may decrease the severity of infection in premature babies, but alternative regimens may be more successful.

Premature babies have low serum immunoglobulin concentrations at birth and do not start producing appreciable amounts of endogenous immunoglobulin until they are at least 15 weeks old. ${ }^{1}$ Premature infants of 32 weeks' gestation or less are particularly compromised, their IgG concentrations being liable to fall to $2 \cdot 0 \mathrm{~g} / \mathrm{l}$ or less as early as six weeks after birth. A baby born at term at a similar postnatal age has a serum IgG concentration of about $6.0 \mathrm{~g} / \mathrm{ll}^{2}$

Despite intensive treatment with antibiotics infection remains an important cause of mortality and morbidity in premature babies. This study aimed to determine whether treatment with intramuscular human normal immunoglobulin could decrease either the morbidity or mortality or both, associated with infection in premature infants.

\section{Patients and methods}

One hundred and twenty preterm babies of 32 weeks' gestation or less, who were consecutively admitted to a regional neonatal unit, were randomised to receive human normal immunoglobulin 50 $\mathrm{mg} / \mathrm{kg}$ intramuscularly weekly $(\mathrm{n}=59)$ or remained untreated $(n=61)$ (table 1$)$. (It would have been unethical to have used a double blind protocol in which the control group received weekly placebo intramuscular injections.) The immunoglobulin, which was prepared by the Blood Products Labora tory, Elstree, and issued by the Central Public Health Laboratory, London, was injected into the lateral aspect of the upper thigh. Blood was sampled for IgG within the first 48 hours of life, before transfusion of blood or any blood products, and then every two weeks until discharge on the first 100 babies. Serum IgG concentrations were measured by a standard centrifugal fast analyser (Encore, Baker Instruments).

All clinically suspected episodes of infection and the results of allied investigations (full blood count,

Table 1 Comparison of groups by gestational age

\begin{tabular}{lll}
\hline $\begin{array}{l}\text { Gestational } \\
\text { age (weeks) }\end{array}$ & $\begin{array}{l}\text { No treated } \\
\text { with human } \\
\text { immunoglobulin } \\
(n=59)\end{array}$ & $\begin{array}{l}\text { No not treated } \\
\text { with human } \\
\text { immunoglobulin } \\
(n=61)\end{array}$ \\
\hline 24 & 2 & 3 \\
25 & 1 & 2 \\
26 & 4 & 6 \\
27 & 5 & 5 \\
28 & 8 & 8 \\
29 & 10 & 8 \\
30 & 13 & 11 \\
31 & 8 & 10 \\
32 & 8 & 8 \\
\hline
\end{tabular}


differential white cell count, culture of blood, urine, and cerebrospinal fluid, and chest $x$ ray picture), were documented for both groups. The investigations were carried out by junior medical staff whenever a deterioration in an infant's condition could not immediately be explained by an acute episode - for example, a pneumothorax, displacement of the endotracheal tube, or extensive intraventricular haemorrhage. The medical staff were not necessarily aware of whether the baby had been treated or not but such knowledge would probably not have prejudiced the study because the response was to a clinical deterioration in the baby's condition and would have been followed through irrespective of whether the baby had been randomised to receive immunoglobulin or not.

Suspected episodes of infection were, in the light of subsequent information, categorised as infection on clinical criteria alone (category A); infection on clinical criteria with supporting laboratory evidence but without positive blood culture (category B), infection confirmed by positive blood culture (category $\mathrm{C}$ ), or as not infective if a satisfactory alternative explanation was found for the baby's deterioration.

The Kolmogorov-Smirnov test was used to determine the normality of the data. Subsequent analysis was by Student's $t$ test or the Mann-Whitney U test as appropriate.

The study was approved by the hospital ethical committee and fully informed parental consent obtained in each case.

\section{Results}

Twelve babies who died within two days of birth and one baby who died when 4 days old (seven in the treatment group and six in the control group) from complications of extreme prematurity (severe intraventricular haemorrhage, severe perinatal asphyxia, pulmonary haemorrhage, pulmonary interstitial emphysema, or pneumothoraces) were not included in the final analysis.

The mean gestational age of the remaining 107 babies was 29.3 weeks (range 24-32), and mean birth weight $1220 \mathrm{~g}$ (range 600-2200). Both groups were comparable for gestational age, birth weight, sex, and length of follow up. There were no significant differences between the groups in the incidence of intraventricular haemorrhage, respiratory distress syndrome, maximum inspiratory pressure, maximum inspired oxygen received, number of days of oxygen supplement given, total time of intermittent positive pressure ventilation, number of days of total parenteral nutrition, time to starting oral feeds, or length of time that umbilical artery catheterisation was required.

Three babies of gestational ages 27, 28, and 30 weeks, all in the control group, died of overwhelming infection. Organisms isolated from blood were Klebsiella pneumoniae and Streptococcus faecalis, coagulase negative staphylococci, and Escherichia coli; the babies died on days 37,19 , and 33 , respectively. Three babies in the same group developed necrotising enterocolitis. The diagnosis was made clinically and from the characteristic radiological appearance of pneumatosis intestinalis in two cases, and confirmed by laparotomy in the third; one of the babies died of the disease six days after the onset.

On 107 occasions clinical deterioration was thought to be due to infection. Confirmatory evidence of infection was absent in 11 instances, and the clinical deterioration was retrospectively attributed to other causes: new and extensive intraventricular haemorrhage $(n=4)$; anaemia $(n=4)$; patent ductus arteriosus $(n=1)$; bronchopulmonary dysplasia $(n=1)$; and metabolic acidosis $(n=1)$. Of the remaining 96 episodes, $34(35 \%)$ were in category A, $16(17 \%$ ) in category B (table 2), and 46 $(48 \%)$ in category $C$ (table 3$)$. By definition the diagnosis of category A infections depended only on a subjective clinical assessment, so these episodes were not included in the subsequent statistical analysis. Details of the number of babies with infection (categories B and C) are shown in table 4.

The proportions of treated and untreated babies who had at least one infective episode in category $B$

Table 2 Supporting evidence for clinical diagnosis of infection in category $B$ infections

\begin{tabular}{ll}
\hline $\begin{array}{l}\text { Age of baby } \\
\text { (days) }\end{array}$ & $\begin{array}{l}\text { Supporting evidence for } \\
\text { clinical diagnosis of infection }\end{array}$ \\
\hline 4 & Consolidation on chest $x$ ray picture \\
& Total neutrophils $0 \cdot 25 \times 10^{9} / 1$ \\
6 & Total white cell count $42 \cdot 6 \times 10^{9} / 1$ \\
7 & Consolidation on chest $x$ ray picture \\
10 & Total neutrophils $16 \cdot 6 \times 10^{9} / 1$ \\
12 & Consolidation on chest $x$ ray picture \\
12 & Total neutrophils $28 \cdot 8 \times 10^{4} / 1$ \\
14 & Consolidation on chest $x$ ray picture \\
17 & Total white cell count $26 \cdot 4 \times 10^{9} / 1$ \\
20 & Total neutrophils $21 \cdot 7 \times 10^{9} / 1$ \\
& (Shift to left) \\
20 & Consolidation on chest $x$ ray picture \\
23 & Consolidation on chest $x$ ray picture \\
28 & Consolidation on chest $x$ ray picture \\
30 & Consolidation on chest $x$ ray picture \\
33 & Consolidation on chest $x$ ray picture \\
40 & Consolidation on chest $x$ ray picture \\
43 & Consolidation on chest $x$ ray picture \\
\hline & Consolidation on chest $x$ ray picture \\
\hline
\end{tabular}


Table 3 Organisms isolated from blood in category $C$ infections

\begin{tabular}{lll}
\hline Organism isolated & $\begin{array}{l}\text { No of cases } \\
\text { in which isolated }\end{array}$ & $\begin{array}{l}\text { Site of } \\
\text { isolation }\end{array}$ \\
\hline $\begin{array}{l}\text { Coagulase negative } \\
\text { staphylococcus }\end{array}$ & 29 (6 in one bottle only) & Blood \\
$\begin{array}{l}\text { S faecalis } \\
\text { Kl pneumoniae } \\
\text { and S faecalis }\end{array}$ & 4 (2 in one bottle only) & Blood \\
Kl pneumoniae & 2 & Blood \\
Klebsiella oxytoci & 1 & Blood \\
S faecalis and & 1 & Blood \\
Staphylococcus aureus & 1 & Blood \\
Enterobacter cloacae & 3 & Blood \\
E coli & 2 & Blood \\
& 1 & Blood \\
Pseudomonas sp & 1 & Brine \\
\hline
\end{tabular}

Table 4 Details of episodes of infection in categories $B$ and $C$
Table 5 Mean serum $\operatorname{Ig} G(g / l)$ concentrations

\begin{tabular}{llll}
\hline Week & $\begin{array}{l}\text { Group treated } \\
\text { with human } \\
\text { immunoglobulin }\end{array}$ & $\begin{array}{l}\text { Group not treated } \\
\text { with human } \\
\text { immunoglobulin }\end{array}$ & $p$ Value \\
\hline 0 & $5 \cdot 3$ & $5 \cdot 0$ & 0.34 \\
2 & $6 \cdot 1$ & $5 \cdot 5$ & $0 \cdot 04$ \\
4 & $4 \cdot 9$ & $4 \cdot 3$ & $0 \cdot 01$ \\
6 & $4 \cdot 1$ & $3 \cdot 2$ & 0.002 \\
8 & 3.6 & $2 \cdot 7$ & $0 \cdot 002$ \\
10 & 3.5 & $2 \cdot 4$ & 0.0002 \\
12 & 3.5 & $1 \cdot 8$ & 0.0002 \\
\hline
\end{tabular}

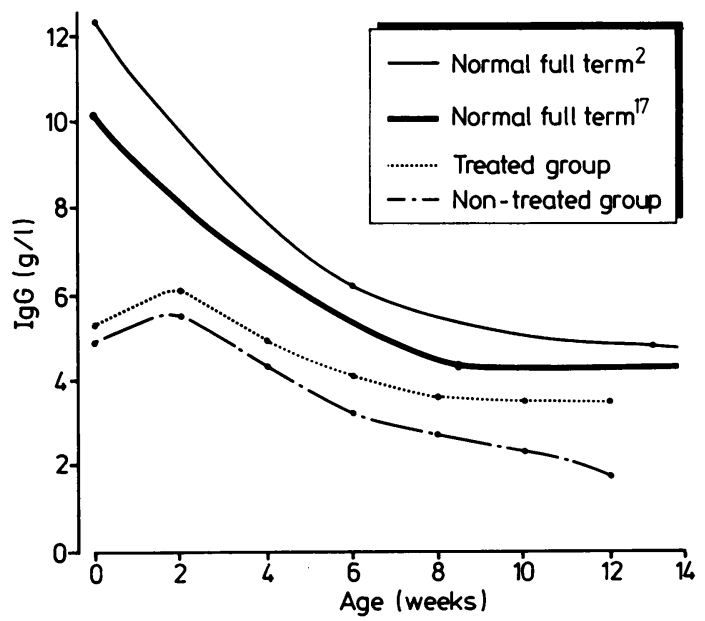

Figure Serum IgG profile in the newborn: comparison of the study population with babies born at term. ${ }^{217}$

or $\mathrm{C}$ were not significantly different $(22 \%$ and $34 \%$, respectively). Similarly, when categories $B$ and $C$ were analysed separately, there was no significant difference between the two groups in the numbers of babies who had at least one episode of infection. Among babies who did have infection, however (categories B and C), the number of episodes in the group who did not receive immunoglobulin $(n=40)$ was significantly greater compared with the treatment group $(n=22), p=0 \cdot 02$. This difference was most pronounced in category $\mathrm{C}$ (28 episodes compared with 18). Analysis of all babies showed that $33(31 \%)$ were of 28 weeks' gestation or less. These infants had $69 \%(p=<0.05)$ of all category $B$, and $72 \%(p=<0.001)$ of all category $C$ infections.

The mean IgG concentrations at birth were comparable in the two groups. By 2 weeks of age the treatment group had significantly greater IgG concentrations (mean $6 \cdot 1 \mathrm{~g} / \mathrm{l}$ ) than the control group (mean $5.5 \mathrm{~g} / \mathrm{l}$ ), and this difference increased with time (table 5). None the less the IgG concentrations achieved with treatment fell consistently below those of a normal baby born at term during the first few weeks of life (figure). 
end of the eighth month of life) ${ }^{8}$ Of seven deaths from infection, only one was in the treated group. The group receiving gammaglobulin also benefited from treatment in that significantly more of them were free of all clinical infection during the study period and the group as a whole had a lower incidence of minor infection. Although the number of severe infections necessitating admission to hospital was not reduced, the treated group spent less time in hospital. Hobbs and Davies gave $250 \mathrm{mg}$ of pooled adult gammaglobulin to several infants of 33 weeks' gestation or less, and though theirs was not a controlled trial, they suggested that the treatment may have conferred some protection against infection in these premature infants. ${ }^{9}$

There are obvious difficulties in diagnosing infection in neonates. A decision to use antimicrobial treatment is often subjective and not subsequently supported by the results of laboratory investigations. We excluded such episodes of presumed infection (category A) from further analysis. Accurate interpretation of radiological changes in the chest $x$ ray pictures of babies requiring assisted ventilation is difficult. When a baby's clinical condition had suddenly deteriorated, however, and in the absence of a mechanical explanation for the observed change, we felt that the appearance of a new confluent shadow was probably due to infection (table 2). Similarly, the result of the neutrophil count may be helpful. ${ }^{10}$

Coagulase negative staphylococci were isolated from $29(63 \%)$ of 46 positive blood cultures (table $3)$. In $23(79 \%)$ cases they were grown from both blood culture bottles and showed uniform antibiotic sensitivities. This ubiquitous skin commensal cannot easily be dismissed as a contaminant in an immunocompromised group subjected to invasive therapeutic techniques. It is recognised as a major cause of hospital acquired infection in neonatal units and is strongly associated with the use of indwelling catheters in premature babies. ${ }^{11} 12$ All our babies had had indwelling venous catheters before developing coagulase negative staphylococcal bacteraemia.

We have shown a substantial difference in the number of infective episodes ( 22 and $40, p=0.02$ ), deaths from infective causes ( 0 and 3 ), and episodes of necrotising enterocolitis ( 0 and 3) between the group treated with immunoglobulin and the group that remained untreated. There was, however, no significant statistical advantage gained from treatment in terms of the number of babies who had at least one infection of either category B or C, suggesting that the treatment did not decrease the susceptibility of the baby to infection.

A compromised humoral immunity is only one of the potentially correctable immune deficiencies in premature babies. We have studied the effect of supplementation with gammaglobulin alone, a support to just one arm of the immature immune system. None the less, IgG accounts for about $80 \%$ of the serum immunoglobulin and is the chief component of a baby's serological defence, containing most of the antibacterial, antiviral, antiprotozoal, and antitoxic activity of the serum. ${ }^{13}$ Many cells (lymphocytes, macrophages, and killer cells) have receptors for IgG, which can also activate the complement system, promote opsonisation, and participate in antibody dependent cytolytic reactions. Faced with a group deficient in IgG and at high risk of severe infection, therefore, it is necessary to evaluate the full effect of supplementation with gammaglobulin in spite of being aware of other immunological deficiencies.

At times of infection and increased catabolism the IgG concentration may fall precipitously. Greater benefit may be obtained if supplementary immunoglobulin is given concurrently with antibiotics at the onset of a suspected infection.

The IgG concentrations achieved in the treated group were significantly greater than those in the control group but none the less remained substantially less than the IgG complement of a term baby in the first few weeks of life. The infants at greatest risk of infection are those of 28 weeks' gestation or less. It is not practical to inject a greater volume of gammaglobulin into the meagre musculature of these premature babies nor to inject it more often. Alternative regimens using intravenous gammaglobulin preparations that are now available may be more successful; high doses are well tolerated. ${ }^{14}$ Hyperimmune preparations may have a role in the prophylaxis of infants at high risk of specific bacterial infection. ${ }^{15}$ Effective early treatment of viral infections may also be achieved. ${ }^{16} \mathrm{We}$ are currently evaluating the possibility that greater protection against infection may result from the rapid achievement and maintenance of IgG concentrations equivalent to those of babies born at term by the administration of intravenous gammaglobulin.

We thank Dr P J Congdon for advice and permission to study his patients, Dr A Milford Ward and the Royal Hallamshire Hospital, Sheffield, for measuring the serum IgG concentrations, Professor R W Smithells for encouragement and advice, Mr A Watkins and Dr A Baines for the statistical analysis, and the regional paediatricians for their cooperation.

\footnotetext{
References

1 Conway SP, Dear PRF, Smith I. Immunoglobulin profile of the preterm baby. Arch Dis Child 1985;60:208-12.

2 Johansson SGO, Berg T. Immunoglobulin levels in healthy children. Acta Paediatr Scand 1967;56:572-9.

${ }^{3}$ Cameron HS. Mouse protection with porcine gamma globulin
} 
against Erysipelothrix Rhusiopathiae. Cornell Vet 1947;37: 336-41.

${ }^{4}$ Cameron HS. The role of plasma fractions in passive immunisation and treatment. Am J Vet Res 1949;10:265-7.

5 Fisher MW, Manning MC. Studies in the immunotherapy of bacterial infections. J Immunol 1958;81:29-31.

${ }^{6}$ Fisher MW. Synergism between human gamma globulin and chloramphenicol in the treatment of experimental bacterial infections. Antibiot Chemother 1957;6:315-21.

${ }^{7}$ Steen JA. Gamma globulin in preventing infections in premature infants. Archives of Paediatrics 1960;77:291-4.

* Amer J, Off E, Ibbott FA, O'Brien D, Kempe CH. The effect of monthly gamma globulin administration on morbidity and mortality from infection in premature infants during the first year of life. Pediatrics 1963;32:4-9.

9 Hobbs RJ, Davis AJ. Serum gamma G-globulin levels and gestational age in premature babies. Lancet 1967;i:757-9.

10 Manroe BL, Weinberg AG, Rosenfeld CR, Browne R. The neonatal blood count in health and disease. 1. Reference values for neutrophilic cells. J Pediatr 1979;95:89-98.

$"$ Munson DP, Thompson TR, Johnson DE, et al. Coagulasenegative staphylococci septicaemia: Experience in a newborn intensive care unit. J Pediatr 1982;101:602-5.
12 Baumgart S, Hall SE, Campos JM, Polin RA. Sepsis with coagulase-negative staphylococci in critically ill newborns. Am J Dis Child 1983;137:461-3.

${ }^{13}$ Stiehm ER. Standard and special human immune serum globulins as therapeutic agents. Pediatrics 1979;63:301-19.

14 Weisman LE, Fischer GW, Hemming VG, Peck CC. Pharmacokinetics of intravenous immunoglobulin in neonates. Pediatr Infect Dis 1986;5:5185-8.

${ }^{15}$ Fischer GW, Hemming VG, Hunger KW, et al. Intravenous immunoglobulin in the treatment of neonatal sepsis: therapeutic strategies and laboratory studies. Pediatr Infect Dis 1986;5: 5171-5.

${ }^{16}$ Hemming VG, Prince GA. Intravenous immunoglobulin G in viral respiratory infections for newborns and infants. Pediatr Infect Dis 1986;5:5204-6.

${ }_{17}$ Stiehm ER, Fudenberg HH. Serum levels of immune globulins in health and disease: a survey. Pediatrics 1966;37:715-27.

Correspondence to Dr S P Conway, Department of Infectious Diseases, Medical Education Centre, Seacroft Hospital, Leeds LS14 6UH.

Received 10 July 1987

Thirty years ago

\section{Wheat gluten and coeliac disease}

Claire Alvey, Charlotte M Anderson, and Mavis Freeman (Melbourne)_Arch Dis Child 1957;32:434-7

After the identification of wheat flour as the cause of coeliac disease by Dicke in Holland in 1950 the search began for the noxious factor in the flour. By 1952-53 it had been confirmed that gluten, the protein fraction of wheat and rye flour, was the cause of the malabsorption. Wheat and rye gluten differ from other cereal proteins in containing more glutamic acid and proline, which can form a type of gel enabling them to be used in breadmaking. The group from Melbourne, noting that the peptide pattern in the gluten molecule is probably associated with the gel property, set out to test the hypothesis that the particular peptide structure of wheat and rye gluten, together with a difference in the enzyme pattern of the patient with coeliac disease, might be responsible for the development of symptoms. Various fractions of gluten were tested. The phospholipid fraction when extracted and fed to a patient with coeliac disease failed to produce an increase in fat excretion. A tryptic digest of gluten to peptides caused a recurrence of steatorrhoea, while neither an amino acid digest or glutamic acid alone had this effect. Blood glutamine concentrations tested two hours after a dose of gluten were found to be three times higher in patients with coeliac disease than in controls, and Weijers and Van de Kamer had reported similar results from feeding gliadin (the $70 \%$ alcohol soluble fraction of gluten).

It was concluded that glutamine itself was not toxic to the patient with coeliac disease but that the toxic fraction was a peptide containing glutamine, and a deficiency of a specific mucosal peptidase that might deaminate the peptide was postulated.

Comment. In the 30 years since the publication of this paper the development of immunology has radically altered our understanding of many disorders. The evidence now points strongly to coeliac disease reflecting an intestinal immune response to gliadin or to peptides from gliadin. The technique of peroral intestinal biopsy was developed by Shiner in 1956, and the characteristic enteropathy of coeliac disease has been shown to be a $T$ cell mediated immune reaction. It has been proposed that lymphocines, secreted by activated $\mathrm{T}$ cells, are the mechanism for $\mathrm{T}$ cell mediated mucosal damage. Other evidence of immunological abnormality is the fact that subjects with isolated $\operatorname{IgA}$ deficiency are particularly prone to develop coeliac disease. We are far from a complete understanding of a complex process and, as yet, we do not have any routine laboratory tests for the measurement of intestinal immune reactions.

(Charlotte Anderson was one of the first, and possibly the most distinguished, among paediatric gastroenterologists. After making outstanding contributions to the specialty both in Melbourne and in the Chair of Paediatrics in Birmingham she has now retired to her native Australia.)

J H HUTCHISON 